\title{
EL RETO DE LA ORDENACIÓN DE LOS MONTES PRIVADOS EN ESPAÑA
}

\author{
Alberto Rojo Alboreca \\ Unidade de Xestión Forestal Sostible (UXFS). Departamento de Enxeñaría Agroforestal. Escola \\ Politécnica Superior. Universidade de Santiago de Compostela. Campus universitario s/n. 27002-LUGO \\ (España). Correo electrónico: alberto.rojo@usc.es
}

\section{Resumen}

En este trabajo se analiza la situación actual de los montes privados en España, cuya importancia queda reflejada en el hecho de que ocupan algo más de 19 millones de ha, lo que representa cerca del $70 \%$ de la superficie forestal nacional. Además, un $84 \%$ de esa superficie forestal privada corresponde a propietarios particulares en régimen individual (montes privados familiares), un $12 \%$ a montes privados colectivos, un $3 \%$ a montes vecinales en mano común y escasamente un $0,6 \%$ a montes privados industriales. Esta distribución de la propiedad forestal privada en España, junto a su importancia superficial, implica la existencia de más de 21,5 millones de parcelas, que corresponden a algo más de 5,2 millones de propietarios, y de las cuales prácticamente el 99\% son menores de 10 ha. Tales cifras implican unos evidentes condicionantes (legales, administrativos y de escala) para la gestión sostenible de este tipo de montes. Uno de ellos es la inadecuación de las figuras de los documentos de ordenación vigentes en la mayor parte del estado, lo que ha desembocado en que solamente un 6,5\% de los montes de titularidad privada españoles cuenten actualmente con algún tipo de instrumento de ordenación. Esta situación supone un enorme reto para el sector forestal nacional, especialmente teniendo en cuenta lo dispuesto en la Ley de montes estatal de 2003 y en su modificación de 2006, que establecen un plazo de 15 años desde su entrada en vigor para la ordenación de todos los montes españoles (públicos y privados), que acaba el 22 de febrero de 2019. Además, en la Ley se establece otro importante plazo de 10 años, que remata el 22 de febrero de 2014, pasado el cual los montes privados no ordenados no podrán acogerse a los incentivos de las administraciones públicas, salvo que se incluyan en el territorio de un plan de ordenación de recursos forestales (PORF). Se comentan las diferentes soluciones aportadas desde las distintas comunidades autónomas (especialmente las de Cataluña, Navarra, Castilla y León y Andalucía) para tratar de ordenar y gestionar adecuadamente sus montes de titularidad privada, que generalmente se basan en simplificar los documentos (sobre todo el inventario) y flexibilizar la planificación, apoyándose en la existencia de planes forestales comarcales o PORFs y en las nuevas tecnologías. También se discute el papel que la certificación forestal ha tenido y puede tener en el futuro en la ordenación de este tipo de propiedades forestales. Finalmente, como ejemplo paradigmático del desafío que supone la ordenación de montes privados, se analiza el caso de Galicia, comunidad con el mayor porcentaje de superficie forestal privada $(97,8 \%)$ del estado. Dos terceras partes de los montes privados gallegos corresponden a montes familiares de menos de 2 ha de tamaño medio (que a su vez se dividen en numerosas parcelas cuya superficie media no alcanza las $0,25 \mathrm{ha}$ ), y el resto a montes vecinales en mano común (con un tamaño medio próximo a las 230 ha). A pesar de esta desfavorable estructura de la propiedad, Galicia aporta anualmente más del $50 \%$ de la madera cortada en España, aunque su territorio apenas supone un 5,8\% de la superficie total nacional. Se comentan las nuevas figuras de instrumentos de ordenación y gestión forestal que se incluyen en la reciente Ley de montes de 
Galicia de 2012, que además del conocido proyecto de ordenación considera documentos simples de gestión para las propiedades de pequeño tamaño, así como documentos compartidos para fomentar las agrupaciones de propietarios. Además, se avanzan detalles de las futuras instrucciones de ordenación gallegas, que describirán y desarrollarán dichas figuras.

Palabras clave: Propiedad forestal, Proyecto de ordenación, Gestión forestal sostenible, PORF, Instrucciones de ordenación, Ley de montes

\section{INTRODUCCIÓN}

En los últimos años se ha tratado y discutido hasta la saciedad sobre la gestión forestal sostenible, especialmente sobre su significado y la manera de medirla y alcanzarla. Aunque ni mucho menos hay unanimidad sobre estos temas, sí parece haber consenso respecto a las enormes implicaciones que tiene en la gestión forestal sostenible la estructura de las propiedades forestales, y concretamente su titularidad, número, tamaño medio y reparto en distintas parcelas.

Cuando se habla de propiedad forestal generalmente se está haciendo referencia al derecho jurídico de libre y exclusivamente utilizar, controlar, transferir o beneficiarse de cualquier otro modo del bosque o de otras superficies forestales, que se puede adquirir por transferencias, tales como ventas, donaciones y herencia. Otras veces, hace referencia a una o más parcelas de bosque o de otras superficies forestales que constituyen una única unidad desde el punto de vista de la gestión o el aprovechamiento (MMAMRM, 2011a).

Como indica en su artículo 11 la Ley de Montes de 2003 (Ley 43/2003, de 21 de noviembre, de Montes; BOE núm. 280, de 22 noviembre de 2003), por razón de su titularidad los montes pueden ser públicos o privados. Son montes públicos los pertenecientes al estado, a las comunidades autónomas, a las entidades locales y a otras entidades de derecho público, mientras que son montes privados aquellos cuya titularidad corresponde a personas físicas o jurídicas de derecho privado, ya sea individualmente o en régimen de copropiedad. Es decir, los montes privados pueden pertenecer a individuos, familias, comunidades, cooperativas, sociedades y otras entidades comerciales privadas, instituciones religiosas, centros privados de enseñanza y fondos privados de pensiones o de inversión, organizaciones no gubernamentales (ONG), asociaciones para la conservación de la naturaleza y otras instituciones privadas (MMAMRM, 2011a).

La Ley de Montes reconoce que los montes vecinales en mano común (figura especial del noroeste de España) tienen una naturaleza especial derivada de su propiedad en común, sujeta a las limitaciones de indivisibilidad, inalienabilidad, imprescriptibilidad e inembargabilidad, indicando que se les aplicará lo dispuesto para los montes privados, sin perjuicio de lo establecido en su legislación especial.

Los últimos informes que incluyen datos de la propiedad forestal en España (SECF, 2011; MAGRAMA, 2012) indican que aproximadamente dos terceras partes de la superficie forestal nacional recae en manos privadas, lo que supone unos 18-19 Mha según la fuente consultada, mientras que las entidades públicas ostentan la propiedad del otro tercio, sumando unos 8,7-9,5 Mha (Tabla 1).

\begin{tabular}{|l|c|c|c|c|}
\hline \multirow{2}{*}{ Titularidad } & SECF (2011) & \multicolumn{3}{|c|}{ MAGRAMA (2012) } \\
\cline { 2 - 5 } & Superficie (x1.000 ha) & \% & Superficie (x1.000 ha) & \% \\
\hline Privada & 18.104 & 65,6 & 19.049 & 68,6 \\
\hline Pública & 9.500 & 34,4 & 8.714 & 31,4 \\
\hline Total & 27.604 & 100,0 & 27.763 & 100,0 \\
\hline
\end{tabular}

Tabla 1. Titularidad de la superficie forestal en España según diferentes fuentes 
Además, se estima que los montes privados ocupan un $71 \%$ de la superficie forestal arbolada nacional y un $75 \%$ de la superficie desarbolada (MAGRAMA, 2010).

La distribución entre superficie forestal pública y privada en las distintas comunidades autónomas es muy desigual. Los porcentajes de titularidad privada oscilan entre el $27 \%$ de la Comunidad Foral de Navarra, el 28\% de Cantabria o el $34 \%$ de La Rioja, hasta el 93\% en Extremadura, el 95\% en las Islas Baleares y casi el 98\% en Galicia, como se muestra en la Figura 1 (MAGRAMA, 2012).

En cuanto a la evolución de la propiedad forestal española, en la Tabla 2 se muestran los datos aportados por el MMAMRM (2011a) para el decenio 1990-2010, pero exclusivamente para la superficie clasificada como Bosque (tierras que se extienden por más de 0,5 hectáreas dotadas de árboles de una altura superior a $5 \mathrm{~m}$ y una cubierta de dosel superior al $10 \%$ o de árboles capaces de alcanzar esta altura in situ; no incluye la tierra sometida a un uso predominantemente agrícola o urbano), e incluyendo en la categoría Otra diferentes formas de propiedad no cubiertas por las categorías pública y privada, más las áreas cuya propiedad no es clara o es disputada.

Las principales variaciones en la propiedad de los terrenos forestales a nivel nacional que se observan en esa Tabla 2 se deben a los cambios relacionados con el incremento de la superficie forestal. En el caso de la superficie forestal arbolada de titularidad privada, su aumento está ligado a la repoblación forestal de las tierras agrícolas y ganaderas marginales, mientras que el aumento de superficie forestal arbolada pública se ha debido principalmente a la colonización arbórea por

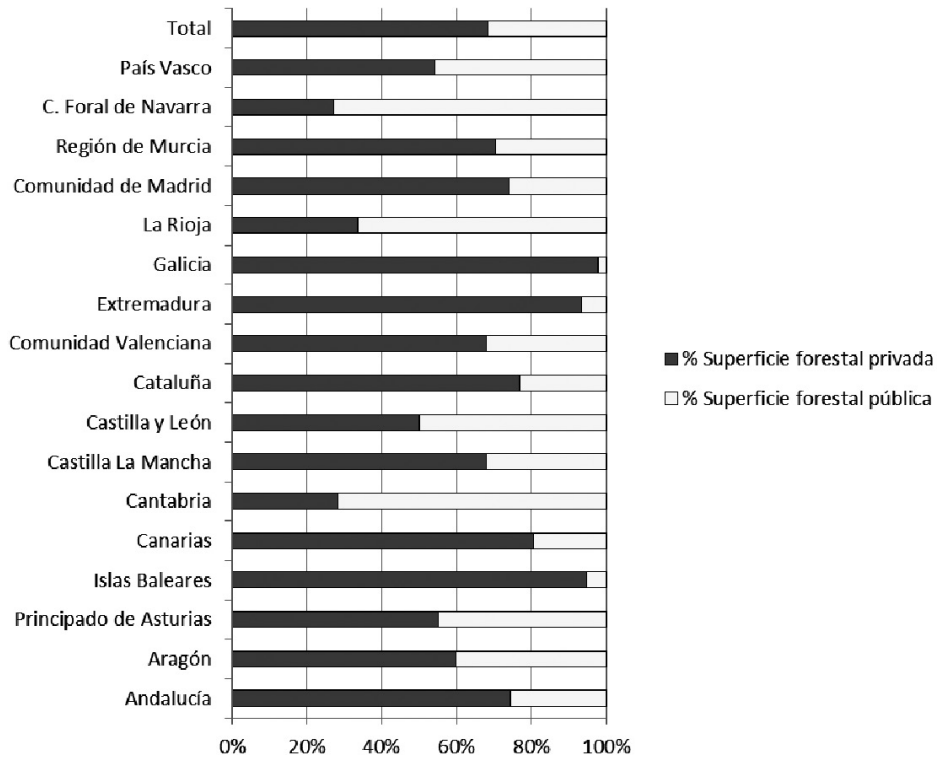

Figura 1. Distribución porcentual de la superficie forestal pública y privada en España por comunidades autónomas (MAGRAMA, 2012)

\begin{tabular}{|l|r|r|r|r|}
\hline Titularidad & $\mathbf{1 9 9 0}$ & $\mathbf{2 0 0 0}$ & $\mathbf{2 0 0 5}$ & $\mathbf{2 0 1 0}$ \\
\hline Pública & $4.332,29$ & $4.987,56$ & $5.077,21$ & $5.335,60$ \\
\hline Privada & $9.486,07$ & $11.998,40$ & $12.214,07$ & $12.835,67$ \\
\hline Otra & 0 & 1,88 & 1,91 & 2,01 \\
\hline
\end{tabular}

Tabla 2. Evolución de la superficie de Bosque (x1.000 ha) en España (MMAMRM, 2011a) 
abandono del pastoreo y a la forestación de terrenos forestales desarbolados (MAGRAMA, 2012).

A nivel mundial, la mayor parte de la superficie forestal en el mundo es de propiedad pública, pues el $84 \%$ de los bosques y el $90 \%$ de otras tierras boscosas son públicos, siendo la Unión Europea la región del planeta con el más alto porcentaje de bosques privados, en torno al $60 \%$ (FAO, 2005; SECF, 2011). La situación en los países europeos es muy diferente: en algunos como Rusia, Bielorrusia, Georgia, Moldavia, Ucrania, Albania y Turquía todos los bosques son públicos; en la zona este de Europa son públicos, en general, más del $80 \%$ de los bosques, mientras que en la zona oeste y en el norte la propiedad pública solamente alcanza, como media, el 30\%. Los países europeos con mayores porcentajes de superficie privada son Austria, Francia, Dinamarca, Noruega, Suecia, Eslovenia, Portugal y España. Respecto a la evolución de la propiedad forestal a nivel europeo, la pública se mantiene desde hace 20 años, mientras que la privada ha aumentado en más del $15 \%$, especialmente en los estados Bálticos y en el centro y este de Europa por la privatización de bosques públicos o la restitución de los bosques a sus antiguos propietarios. La propiedad privada europea está principalmente orientada a la producción de madera en rollo o de otros productos con gran valor de mercado, mientras que en la propiedad pública hay una mayor producción de leñas y de bienes y servicios (MMAMRM, 2011a).

Volviendo a España, el reparto pormenorizado de las superficies forestales privadas y públicas se muestra en la Figura 2 (SECF, 2011), aunque es necesario señalar, como indica el
MAGRAMA (2012), que no se cuenta con suficiente información para caracterizarlas adecuadamente en la mayor parte del país, especialmente en el ámbito privado, a pesar de que en la última década, y gracias al desarrollo de los sistemas de información geográfica, empieza a superarse tal carencia de conocimiento, al menos en algunas comunidades autónomas.

En esa Figura 2 se observa que los ayuntamientos son propietarios de la mayor parte de la superficie forestal pública, con un porcentaje muy superior al correspondiente al estado o a las comunidades autónomas. Además, cerca de 6,8 Mha de esa superficie pública forestal tienen carácter demanial y se encuentran incluidas en el Catálogo de montes de utilidad pública.

En cuanto a la superficie forestal privada española, la mayor parte corresponde, con gran diferencia, a propietarios particulares en régimen individual (montes privados familiares), que suman un $55 \%$ del total (y, por tanto, un $84 \%$ respecto a la superficie privada), un $8 \%$ a montes privados colectivos (montes de propios), un $2 \%$ a montes vecinales en mano común y escasamente un $0,4 \%$ a montes privados industriales, cuyo único caso representativo en la actualidad es ENCE, pues entre 1950 y 1980 los patrimonios forestales industriales han ido desapareciendo (SECF, 2011).

Esta distribución de la propiedad forestal privada en España, junto a su importancia superficial, implica la existencia de más de 21,5 millones de parcelas, que corresponden a algo más de 5,18 millones de propietarios, y de las cuales prácticamente el $99 \%$ son menores de 10 ha (MMAMRM, 2011a), como se muestra en la Tabla 3. Por tanto, la propiedad forestal privada
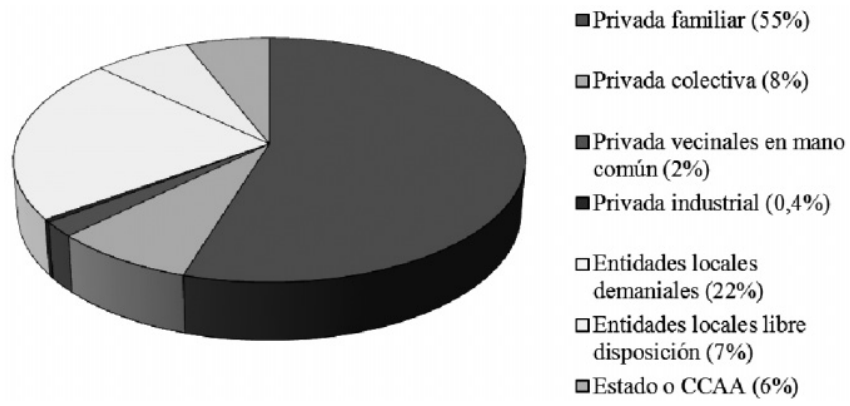

Figura 2. Reparto porcentual de la superficie forestal en España según su titularidad (SECF, 2011) 
española está fundamentalmente formada por "minifundios forestales".

Respecto a los datos de la Tabla 3, conviene recordar, como indica el propio MMAMRM (2011a), que la cartografía de propiedad pública es mucho más precisa que la de propiedad privada (que se completa por defecto), que la información de las propiedades por tamaño procede de una consulta al catastro del año 2001, y que se corresponde con el número de parcelas, lo que no representa ni el número de propietarios ni el de explotaciones, ya que lo más común es que varias parcelas sean de un mismo propietario.

En cualquier caso, tales cifras implican unos evidentes condicionantes para la gestión sostenible de los montes privados españoles. Esos condicionantes son, por una parte, de tipo legal y administrativo, pues una gran proporción de las parcelas que los forman no tiene la propiedad consolidada o se desconoce a sus titulares. Este hecho está ligado a la falta de información catastral relativa a los terrenos forestales (SECF, 2011), y también, en gran medida, al envejecimiento de los propietarios forestales y a su mayor ocupación fuera del sector forestal y agropecuario, aspectos comunes en toda Europa y que serán determinantes en el futuro de la estructura de la propiedad forestal (HIRSCH et al., 2007).

Por otra parte, la tremenda fragmentación y el pequeñísimo tamaño de la gran mayoría de las parcelas que forman las propiedades privadas representan un importante condicionante de escala para conseguir una gestión efectiva y, por consiguiente, una rentabilidad económica. La principal motivación de la gran mayoría de propietarios para gestionar sus terrenos forestales, ya sean grandes o pequeños, es de tipo económico, y si no les resulta rentable actuar en sus montes acaban por no gestionarlos y por abandonarlos. Este problema resulta mucho mayor, y más difícil de solucionar, en el caso de las fincas de pequeño tamaño, pues en ellas es bastante más complicado rentabilizar las actuaciones forestales, que ya de por sí son, en general, poco rentables desde el punto exclusivamente económico. La rentabilidad económica representa uno de los tres pilares de la sostenibilidad (junto con el respeto medio ambiental y los beneficios sociales), por lo que si falla la misma no es posible conseguir una gestión en los minifundios forestales que se pueda calificar de sostenible.

A pesar de estos condicionantes, el 80,4\% de las cortas a nivel nacional se producen en los montes privados (MAGRAMA, 2010), como se muestra en la Tabla 4 (datos de 2010), lo que sin duda se debe a la elevada superficie que ocupan en el total nacional (Tabla 1). Además, en los montes privados se corta aproximadamente el $25 \%$ de la madera de coníferas del estado y el $92 \%$ de la madera de frondosas, de las cuales prácticamente el $81 \%$ corresponde a eucalipto (MAGRAMA, 2010), lo que resulta claramente indicativo de dónde se localizan los montes privados productivos.

El análisis más detallado de las cortas en las propiedades forestales privadas españolas

\begin{tabular}{|l|r|r|r|r|}
\hline \multirow{3}{*}{$\begin{array}{l}* \\
\text { categorías de tamaño }\end{array}$} & Tamaño (ha) & Pública & Privada & Total \\
\cline { 2 - 5 } & $<10$ & $91,33 \%$ & $98,89 \%$ & $98,51 \%$ \\
\cline { 2 - 5 } & $11-100$ & $7,65 \%$ & $1,04 \%$ & $1,37 \%$ \\
\cline { 2 - 5 } & $>101$ & $1,02 \%$ & $0,07 \%$ & $0,12 \%$ \\
\hline $\mathrm{N}^{\circ}$ total & & 1.160 .617 & 21.572 .241 & 22.732 .858 \\
\hline $\mathrm{N}^{\circ}$ total de propietarios & $1 \%$ & $99 \%$ & 5.242 .432 \\
\hline
\end{tabular}

Tabla 3. Distribución por categorías de tamaño de las parcelas que conforman la propiedad forestal en España y número de propietarios (MMAMRM, 2011a)

\begin{tabular}{|l|r|r|}
\hline Titularidad & Cortas ${\left(\mathbf{m}^{3} \text { c.c. }\right)}^{\text {(1) }}$ & \% \\
\hline Pública & 2.339 .555 & 19,6 \\
\hline Privada & 9.612 .058 & 80,4 \\
\hline Total & 11.951 .613 & 100,0 \\
\hline
\end{tabular}

Tabla 4. Volumen de cortas por tipo de propiedad en España en 2010 (MAGRAMA, 2010) 
indica que un $69,6 \%$ del total nacional corresponde a montes sin consorcio ni convenio, un $8,8 \%$ a montes vecinales en mano común, un $1,1 \%$ a montes consorciados o conveniados, $y$ de un $0,9 \%$ se desconoce su origen (MAGRAMA, 2010).

Uno de los aspectos ligados al anteriormente mencionado condicionante de escala es la inadecuación a las propiedades de pequeño tamaño de los instrumentos de gestión forestal (proyectos de ordenación de montes, planes dasocráticos, planes técnicos $\mathrm{u}$ otras figuras equivalentes, según la Ley de Montes) vigentes en una gran parte del estado. Esto ha desembocado en que solamente una muy pequeña proporción de los montes de titularidad privada españoles se encuentran ordenados, como se indica en la Tabla 5, en la que se muestran los últimos datos disponibles sobre la superficie sujeta a instrumentos de gestión forestal de cualquier tipo en España (MAGRAMA, 2010).

Como puede observarse, en España existen actualmente cerca de 3,4 Mha ordenadas, lo que representa escasamente el $12,4 \%$ de la superficie forestal nacional. De esa superficie ordenada, poco más de una tercera parte corresponde a montes privados, pero como este tipo de propiedad tiene mayor representación en el conjunto del estado (Tabla 1), resulta que únicamente el $6,5 \%$ de la superficie forestal particular cuenta en la actualidad con un instrumento de gestión forestal, frente a casi el $28 \%$ de la pública (MAGRAMA, 2010).

En la Figura 3 se muestra el porcentaje de las superficies públicas y privadas ordenadas en cada comunidad autónoma (MAGRAMA, 2010), aunque no existen datos de superficie privada ordenada en Aragón, Islas Baleares, Cantabria, Comuni-

\begin{tabular}{|l|r|r|}
\hline Titularidad & Superficie ordenada (ha) & \% \\
\hline Privada & 1.296 .485 & 37,81 \\
\hline Pública & 2.132 .858 & 62,19 \\
\hline Total & 3.429 .343 & 100,00 \\
\hline
\end{tabular}

Tabla 5. Superficie sujeta a instrumentos de ordenación en España según titularidad (MAGRAMA, 2010)

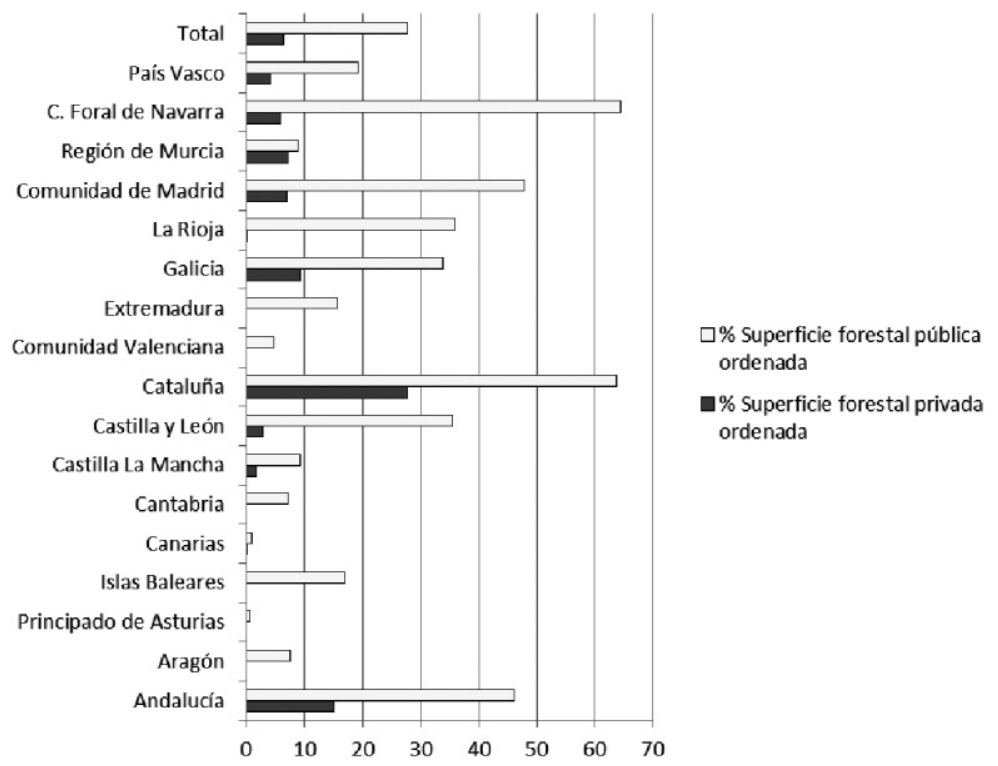

Figura 3. Distribución porcentual de la superficie pública y privada ordenada en España por comunidades autónomas (MAGRAMA, 2010) 
dad Valenciana y Extremadura. Como se aprecia en esa Figura 3, destacan la Comunidad Foral de Navarra, Cataluña, la Comunidad de Madrid y Andalucía en lo que respecta a los montes públicos, aunque en ningún caso se superan las dos terceras partes ordenadas. Los porcentajes de montes privados ordenados son muchos menores, destacando nuevamente Cataluña $(27,8 \%)$ y Andalucía $(15,2 \%)$, mientras que en el resto de las comunidades autónomas no se alcanza el $10 \%$.

Otra cuestión, no recogida en las estadísticas, es la proporción de estos "teóricos montes ordenados" que no tienen vigente el correspondiente instrumento de gestión forestal, por lo que los porcentajes reflejados en la Figura 3 podrían ser aún menores.

La evolución de la superficie ordenada en España en los últimos 20 años según el MMAMRM (2011a) se muestra en la Tabla 6, donde se puede comprobar que se ha incrementado muy poco en ese período (un escaso $3 \%$ ) la superficie gestionada con instrumentos de ordenación, y muy especialmente si se compara con el aumento del $31 \%$ de la superficie de bosque en esos mismos años.

A nivel europeo, y aunque existen diferencias considerables de forma y contenido entre los planes de los distintos países, la última información disponible (que corresponde al $77 \%$ del área forestal europea sin la Federación Rusa) indica que el $90 \%$ de los bosques están gestionados por algún tipo de instrumento de ordenación, habiéndose incrementado ligeramente este porcentaje en los últimos 10 años, y que España es el país europeo con menor porcentaje de superficie ordenada de bosque (MMAMRM, 2011a).

Finalmente, también resulta interesante examinar las estadísticas referentes a certificación forestal, puesto que es condición imprescindible, aunque no suficiente, disponer de un instrumento de gestión vigente para obtener el certificado por cualquiera de los dos sistemas implantados en España: FSC (Forest Stewardship Council) y PEFC (Programme for the Endorsement of
Forest Certification schemes). La información procedente de las páginas Web de ambos sistemas (abril de 2013) indica que en España existen 160.155 ha certificadas por FSC y 1.606 .436 ha por PEFC. Estas cifras representan, respectivamente, unos escasos porcentajes del 0,9 y $8,8 \%$ de la superficie forestal arbolada nacional, muy lejos de las de otros países con mucha mayor tradición forestal, como Finlandia o Suecia.

A nivel de comunidades autónomas, la mayor superficie certificada por FSC corresponde a Andalucía, con más de 103.000 ha, que representan casi el $65 \%$ del total certificado por este sistema en España. En el caso del PEFC, la mayor superficie certificada se encuentra en Castilla y León, con algo más de 624.000 ha y un $39 \%$ del total certificado a nivel nacional por este sistema. Sin embargo, la Comunidad Foral de Navarra es la que posee un mayor porcentaje de superficie arbolada certificada, en torno al 52\% (Olabe, 2013). Es importante señalar que en algunas comunidades autónomas una parte de la superficie forestal con gestión forestal certificada cuenta con acreditación por ambos sistemas.

\section{EL RETO DE LA ORDENACIÓN DE LOS MONTES PRIVADOS}

Teniendo en cuenta los datos expuestos en el apartado anterior, parece razonable incidir en el esfuerzo por ordenar los montes españoles, y que ese esfuerzo debe redoblarse en el caso de los montes privados, pues es en ellos en los que existe una mayor carencia de instrumentos de gestión y una mayor dificultad para dotarles de los mismos. Esa dificultad se debe principalmente, como se ha señalado, a la atomizada estructura de la propiedad, lo que condiciona que las instrucciones de ordenación vigentes en una gran parte del estado no se adapten a las características de los montes privados de pequeño tamaño.

La estructura de la propiedad forestal en España es un limitante que resulta muy compli-

\begin{tabular}{|l|r|r|r|r|}
\hline \% ordenado & $\mathbf{1 9 9 0}$ & $\mathbf{2 0 0 0}$ & $\mathbf{2 0 0 5}$ & $\mathbf{2 0 1 0}$ \\
\hline Bosque & 18,65 & 18,79 & 20,03 & 19,29 \\
\hline Total forestal & 9,98 & 11,67 & 12,57 & 12,09 \\
\hline
\end{tabular}

Tabla 6. Evolución del porcentaje de la superficie ordenada en España (MMAMRM, 2011a) 
cado, o imposible, de cambiar o solventar. Muchas veces se habla de la agrupación de propietarios y de la concentración parcelaria de sus terrenos como una solución, pero la realidad ha demostrado que es un proceso muy lento, complejo y costoso, por lo que únicamente algunos casos han conseguido llegar a resultados satisfactorios, como la concentración en el ayuntamiento de Trabada (Lugo), pero no dejan de ser la excepción que confirma la regla.

Por tanto, parece más razonable fijar el esfuerzo en conseguir adaptar la normativa relativa a los instrumentos de gestión a las características y necesidades de los minifundios forestales dominantes en España.

Las Instrucciones Generales para la Ordenación de Montes Arbolados (IGOMA), aprobadas por Orden Ministerial de 29 de diciembre de 1970 (BOE núm. 36, de 11 de febrero de 1971), así como las Normas Generales para el estudio y redacción de los Planes Técnicos de Montes Arbolados (NGPTMA), aprobadas por Orden Ministerial de 29 de julio de 1971 (BOE núm. 192, de 12 de agosto de 1971), siguen vigentes en gran parte del Estado español, salvo en aquellas comunidades autónomas que han aprobado unas propias. Estas instrucciones fueron pensadas para ordenar montes de mediano o gran tamaño, como los de utilidad pública, y no para los minifundios forestales que representan los montes privados de pequeño tamaño. Resulta evidente la necesidad de actualizar las IGOMA y la NGPTMA más de 40 años después de su entrada en vigor, pues desde entonces han sido muchos los cambios en las demandas de la sociedad frente a los montes y los avances en el conocimiento del funcionamiento y manejo de los sistemas forestales (MADRIGAL, 1994).

La Ley de Montes de 2003 y su modificación de 2006 (Ley 10/2006, de 28 de abril, por la que se modifica la Ley 43/2003, de 21 de noviembre, de Montes; BOE núm. 102, 29 abril 2006) reconocen la enorme importancia de ordenar los terrenos forestales. Para ello, establecen en el Art. 32 que el Gobierno aprobará unas Directrices básicas comunes de ordenación y aprovechamiento de montes, que deben incluir, entre otras cosas, el contenido mínimo de los proyectos de ordenación y planes dasocráticos, así como el de las instrucciones de ordenación y aprovechamiento de montes que, posteriormente, deberán aprobar las comunidades autónomas. Diez años después de la aprobación de la Ley de Montes, y siete años después de su modificación, no se han elaborado dichas Directrices básicas comunes, y la única referencia encontrada a las mismas corresponde a un reciente trabajo de ADELL y FERNÁNDEZ (2013), que presentan una propuesta, muy sucinta, de su estructura. Como curiosidad, es la primera vez en la historia forestal española que la actualización de las instrucciones de ordenación sobrepasa el límite de 40 años, intervalo máximo acaecido, y el más repetido, entre la aprobación de las anteriores normas dasocráticas: 1857, 1890, 1930, 1970 y ¿?

Afortunadamente, como se comenta en el siguiente apartado, varias comunidades autónomas han tomado la iniciativa y han aprobado instrucciones o normas propias de ordenación, han simplificado y abaratado los instrumentos de gestión o han creado otros nuevos específicos para las propiedades privadas, pero en cualquier caso queda mucho camino por recorrer.

Por lo tanto, la necesidad de ordenar los montes españoles, y especialmente los privados, supone un enorme reto para el sector forestal nacional, pero sobre todo teniendo en cuenta la Disposición transitoria segunda (Plazo para la ordenación de montes) de la Ley de Montes de 2003, que establece un plazo de 15 años desde su entrada en vigor para la ordenación obligatoria de todos los montes españoles (públicos y privados), que acaba exactamente el 22 de febrero de 2019. Quedan exentos de esta obligación aquellos montes de superficie inferior al mínimo que las comunidades autónomas pueden determinar de acuerdo con las características de su territorio forestal. Hay que hacer notar que en la Ley de 2003 esta obligatoriedad solamente hacía referencia a los montes públicos, y que en la modificación de la Ley de 2006 se incluyeron también a los privados.

Además, en la Disposición transitoria tercera de la Ley de Montes (Incentivos económicos en montes no ordenados) se establece otro importante plazo de 10 años, que finaliza el 22 de febrero de 2014, pasado el cual los montes no ordenados no podrán acogerse a los incentivos de las administraciones públicas, salvo que se incluyan en el territorio de un Plan de ordenación de recursos forestales (PORF). 
Parece razonable pensar que dichos plazos no se van a cumplir, o al menos el primero, a la vista de la evolución de la superficie ordenada en España y a la paradoja de que la propia administración no haya prestado hasta el momento mayor interés en la elaboración de las comentadas Directrices básicas comunes de ordenación y aprovechamiento de montes. Incluso existe un borrador de modificación de la Ley de Montes en el que se propone alargar ambos plazos.

Por otra parte, un importante aspecto a considerar es el escaso conocimiento o cultura forestal de una gran parte de los propietarios privados, especialmente teniendo en cuenta su elevada edad media y que muchos viven en las ciudades. Por esa razón, cualquier intento de implantar unos instrumentos de gestión en los montes privados debe ir acompañado necesariamente de una inmensa labor de extensión forestal, con el objetivo de enseñar a los propietarios el significado, la importancia y las maneras de conseguir una gestión sostenible de sus propiedades.

\section{EL PAPEL DE LA CERTIFICACIÓN FORESTAL}

A pesar de las consideraciones anteriores, el momento actual resulta esperanzador para la ordenación de montes, tanto por la comentada importancia que le asigna la Ley de Montes como por la creciente atención que está prestando la sociedad a la gestión forestal, que se está haciendo "visible" gracias a, entre otras causas, la certificación.

Efectivamente, la certificación forestal está empezando a tener un importante papel en la ordenación de los montes españoles, y puede ser un gran acicate para conseguir ordenar las propiedades forestales privadas. Como ya se ha comentado, un requisito indispensable, pero no suficiente, para conseguir la certificación por cualquiera de los dos sistemas implantados en España (FSC y PEFC) es contar con un plan de gestión vigente.

Aunque la certificación es un proceso voluntario, el mercado empieza a reclamar determinados productos certificados, lo que está suponiendo un importante sobreprecio respecto al mismo producto sin certificar. Este es el caso, por ejemplo, de la madera de eucalipto para pasta de celulosa, que en la actualidad está alcanzando en el noroeste de
España sobreprecios de hasta $6 €$ por tonelada si cuenta con el sello FSC. Este hecho ha despertado el lógico interés de los productores de madera, que en el caso del eucalipto de Galicia y la Cornisa Cantábrica son mayoritariamente propietarios privados de pequeñas superficies. La única vía que tienen estos propietarios para conseguir certificarse pasa por agruparse y acudir a las modalidades de certificación SLIMF (Small and Low Intensity Managed Forests, o Pequeña propiedad forestal y monte de baja intensidad de gestión, en el caso del FSC) o regional (en el caso del PEFC), que pretenden simplificar y facilitar el acceso a la certificación de este tipo de propiedades. De esta manera, la "necesidad" de certificación está obligando a agruparse a los propietarios de pequeñas superficies forestales, a dotarse de algún tipo de instrumento de gestión y a mantenerlo vigente. Por esa razón, los dos sistemas de certificación, aunque de forma independiente, han trabajado intensamente buscando modelos de planes de gestión sencillos o simplificados, baratos de elaborar y aplicables a las pequeñas propiedades. De esta manera, se han adelantado a las administraciones forestales de algunas comunidades autónomas, que deberían haber sido las encargadas de dicha tarea. Ejemplos de este hecho se pueden encontrar, por ejemplo, en AZPITARTE (2013) y en CANTERO (2013).

Desde hace unos pocos años existen varias certificaciones regionales por el sistema PEFC en distintas comunidades autónomas, pero de momento solamente se ha iniciado el proceso de certificaciones grupales de pequeñas propiedades en el caso del FSC. Sin embargo, son muy significativas las dos primeras iniciativas grupales tipo SLIMF certificadas por este sistema, que se localizan en la comarca de Ortegal (norte de la provincia de A Coruña) y que corresponden a PROMACER (Asociación de Productores de Madeira de Cerdido), con 532,86 ha repartidas en 1.952 parcelas de 68 propietarios, y a XEFOSNOR (Grupo de Xestión Forestal Sostible do Norte), con 1.275 ha divididas en 6.532 parcelas de 207 propietarios (GONZÁLEZ-TATO et al., 2013).

En definitiva, la certificación está consiguiendo, de momento en algunos casos, que los propietarios de montes de muy pequeño tamaño se agrupen y se ordenen, algo impensable hasta hace poco. Dada la creciente demanda de productos forestales certificados, es previsible que 
en los próximos años aumente de forma notable la superficie de minifundios forestales ordenados y certificados en España.

\section{SOLUCIONES APORTADAS DESDE LAS COMUNIDADES AUTÓNOMAS}

La creación de instrumentos de gestión específicos para la ordenación de montes privados corresponde legislativamente a las comunidades autónomas según la Ley de Montes, como ya se ha comentado. Pero también se ha indicado que la propia Ley prevé un paso anterior consistente en la aprobación a nivel estatal de unas, hasta ahora inexistentes, Directrices básicas comunes de ordenación y aprovechamiento de montes, en las que deberían basarse las instrucciones de ordenación autonómicas. A falta de esas directrices, varias comunidades autónomas han tomado la iniciativa (varias de ellas desde mucho antes de la aprobación de la Ley de Montes de 2003) $\mathrm{y}$ han aportado diferentes soluciones para tratar de ordenar y gestionar adecuadamente sus montes de titularidad privada, comentándose a continuación las más notables.

Cataluña posee un $77 \%$ de su superficie forestal de titularidad privada (Figura 1), repartida en propiedades de 28 ha de tamaño medio (Portabella et $a l ., 1995$ ), y es sin ninguna duda la comunidad autónoma más activa, y la pionera, en la promulgación de normas o instrucciones de ordenación dirigidas a los montes privados. Así, hace más de 20 años creó el primer instrumento de gestión específico para los montes privados: los Planes Técnicos de Gestión y Mejora Forestal (PTGMF), mediante la Orden de 10 de junio de 1991 (DOGC núm. 1246, del 3 de julio de 1991). Esas Instrucciones generales para la redacción, aprobación y revisión de los PTGMF fueron actualizadas y modificadas en distintas ocasiones, y en 2003 se creó una segunda modalidad de instrumento de gestión, los Planes Simples de Gestión Forestal (PSGF), para las fincas privadas de tamaño inferior a 25 ha (Orden MAB/394/2003, de 18 de septiembre de 2003; DOGC núm. 3981, de 6 de octubre de 2003). Desde entonces también ha habido modificaciones de la norma referida a los PTMGF y los PSGF, y finalmente en 2011 se han aprobado las Instrucciones para la redacción de instrumentos de ordenación forestal correspondientes a fincas de titularidad privada (Resolución AAM/1302/2011, de 6 de mayo; DOGC núm. 5889, de 30 de mayo de 2011).

Por tanto, en Cataluña existen dos instrumentos de gestión dirigidos fundamentalmente a la ordenación de los montes privados: los PTGMF y los PSGF.

Los PTGMF fueron creados a medio camino entre el modelo francés de Plan Simple de Gestión y el de los Planes Técnicos de Montes Arbolados de 1971 (PorTABELla et al., 1995). Consideran una planificación para un período de 10 a 30 años y poseen un contenido simplificado, estructurado en once capítulos: nueve correspondientes a la descripción de los datos generales y de la planificación, uno con las fichas descriptivas de cada unidad de actuación, y el último con la cartografía. Se pueden aplicar para la gestión de una o varias fincas de un único propietario o de una agrupación de propietarios que, en conjunto, sumen una superficie a ordenar igual o superior a 25 hectáreas. Las instrucciones no indican ni dan prioridad a ningún método de ordenación, por lo que la gestión se organiza y concreta en cada una de las unidades de actuación en las que se divide el monte, cada una de las cuales puede tener objetivos y actuaciones diferentes a las del resto.

Los Planes Simples de Gestión Forestal (PSGF) tienen la misma finalidad que los PTGMF, pero se refieren a fincas forestales con una superficie ordenada inferior a 25 hectáreas, por lo que su contenido es todavía más reducido y se estructuran en siete capítulos (incluyendo cartografía y otros documentos específicos si son necesarios).

Las mencionadas instrucciones catalanas para fincas privadas de 2011, que desarrollan la estructura y contenido de los PTGMF y los PSGF, se apoyan en el uso de varios documentos de referencia que sirven de ayuda y dan cobertura a las propuestas de planificación (FARRIOL, 2013). Dichos documentos son las Orientaciones de gestión multifuncional para bosques de Cataluña (ORGEST), que incluyen un catálogo de tipologías forestales arboladas y un conjunto de modelos de gestión asociados a cada tipología y según objetivos (PIQUÉ et al., 2013); el Manual 
de soporte para la estimación pericial en el trabajo de campo; y las Instrucciones de redacción e inventario forestal. Además, se han desarrollado una serie de programas informáticos gratuitos para ayudar a la redacción de los PTGMF y los PSGF y para facilitar y agilizar los trámites administrativos de aprobación, ejecución y seguimiento de los trabajos propuestos. Dichos programas son el sistema de información geográfica MIRAMON, que permite hacer la cartografía digital, el programa LIFOR Cataluña, que realiza el manejo y procesado de los datos de los inventarios, y el programa METABOSC, desarrollado para facilitar la redacción de los documentos y al que se vinculan los dos programas anteriores (FARRIOL, 2013).

Con la idea de que los propietarios entiendan y se identifiquen con los PTGMF y los PSGF, para asegurar su aplicación exitosa, pueden ser redactados, revisados y firmados por ellos mismos (cuando son redactados por un ingeniero es necesaria también su firma). Además, otra manera de involucrar a los propietarios en la gestión de sus fincas son las importantes ventajas y derechos que adquieren cuando se les aprueba un PTGMF o un PSGF (CPF, 2013): conversión en miembro de pleno derecho del Centro de la Propiedad Forestal de Cataluña (CPF); agilidad e integración de los trámites administrativos relativos a la gestión forestal; asesoramiento técnico pluridisciplinar en el desarrollo de la planificación aprobada y en la gestión de la explotación forestal; posibilidad de actualizar y modificar la planificación aprobada de acuerdo con los objetivos fijados; revisión de la planificación a partir de los cinco años de vigencia o por circunstancias extraordinarias; acceso a beneficios fiscales (transmisiones patrimoniales, donaciones, herencias, IRPF, etc.); prioridad al acceso a las ayudas forestales, con incrementos de un $20 \%$ a un $30 \%$ con respecto a las fincas sin PTGMF o PSGF; y acceso a los seguros de responsabilidad civil y de incendios forestales.

Pero a su vez, los propietarios con un PTGMF o PSGF aprobado también se comprometen a cumplir con los siguientes deberes (CPF, 2013): ejecutar correctamente los trabajos aprobados, de acuerdo con la normativa forestal, las técnicas selvícolas descritas en los planes y los condicionantes que se hayan podido establecer; comuni- car por escrito, antes del inicio de su ejecución, cualquier trabajo previsto en el plan con un plazo mínimo de 10 días de antelación; solicitar al CPF la modificación de los planes para poder incluir trabajos no previstos inicialmente, o con el fin de cambiar la forma de ejecución de los ya aprobados para adaptar la planificación a hechos coyunturales de la finca; comunicar al CPF los cambios de titularidad o de configuración de la finca (compra-venta, donación, herencia, segregación, etc.) o cualquier otra circunstancia que pueda afectar a la ejecución o la vigencia del PTGMF o PSGF; y tramitar el cuestionario para la construcción de pistas forestales en parajes de especial interés natural (PEIN).

El resultado conseguido con la aplicación de los PTGMF y los PSGF ha sido muy relevante, pues los últimos datos indican que hay aprobados 2.885 PTGMF, correspondientes a 423.030 hectáreas, y 259 PSGF que representan otras 3.132 hectáreas, que en su conjunto representan el $29 \%$ de la superficie forestal privada de Cataluña ( FARRIOL, 2013), lo que la sitúa como la comunidad autónoma con mayor porcentaje de montes privados ordenados de todo el estado (Figura 3).

Gran parte de la responsabilidad en el éxito de la aplicación de los PTGMF y PSGF se debe a la labor del Centro de la Propiedad Forestal de Cataluña (CPF), que es un órgano descentralizado del Departamento de Agricultura, Ganadería y Pesca de la Generalitat de Cataluña creado en 1998 y que posee competencias en la ordenación, el fomento y la gestión de los terrenos forestales de titularidad privada. Entre otras muchas tareas, el CPF presta apoyo técnico y económico a la redacción de los PTGMF y PSGF y ha realizado una importante misión de extensión forestal entre los propietarios privados catalanes.

Por otra parte, Cataluña está trabajando en unas nuevas instrucciones para la elaboración de los proyectos de ordenación, que se comentan en GARCíA et al. (2013), especialmente pensando en los montes públicos, pero todavía no se ha producido su aprobación, por lo que en lo relativo a los proyectos de ordenación siguen vigentes las IGOMA de 1970.

En la Comunidad Foral de Navarra no existen unas instrucciones de ordenación propiamente dichas, pero la redacción de los instrumentos 
de gestión forestal se regula mediante los Pliegos de Condiciones Técnicas Generales de Ordenación de Montes (ERASo y Olabe, 1998). Estos Pliegos son más flexibles que un documento con rango normativo, lo que ha permitido actualizarlos periódicamente, como consecuencia de la experiencia en su propia aplicación y para adaptarlos a nuevas necesidades, como por ejemplo las relacionadas con la certificación o con los espacios naturales protegidos. En este documento se describe el contenido básico de los Proyectos de ordenación y de los Planes técnicos de gestión, indicando los aspectos de mayor interés para la administración, que deben ser tratados detenidamente. Se busca de este modo que sean documentos prácticos y flexibles, y en ellos no se descarta el empleo de ningún método de ordenación (ni siquiera se mencionan los que se pueden aplicar), pero se orientan claramente hacia la ordenación por rodales, método utilizado en la gran mayoría de los montes navarros (MONTERO, 2008; Olabe, 2013).

Los resultados de aplicar los Pliegos durante el período 1998-2010 indican que Navarra ha conseguido ordenar casi un $65,5 \%$ de sus montes públicos (el porcentaje más alto de todas las comunidades autónomas), aunque solamente un $6 \%$ de sus montes privados (Tabla 3 ), que poseen una superficie media por propietario en torno a las 2,5 ha. Además, un $52 \%$ de la superficie forestal arbolada de Navarra se encuentra certificada. Sin ninguna duda, estos buenos resultados han sido posibles gracias al acompañamiento de una política de ayudas a la elaboración de proyectos de ordenación (OlABE, 2013).

A pesar de este éxito, y de la utilidad práctica de los proyectos de ordenación elaborados en Navarra, se constató que seguían siendo caros, laboriosos y complejos, incluyendo excesiva información, innecesaria o reiterativa entre distintos proyectos cuando se trataba de aspectos no exclusivos del monte ordenado. Además, también se comprobó que las figuras de planificación forestal no daban respuesta a los terrenos muy fragmentados de propiedad privada, a pesar de la existencia de algunas agrupaciones forestales. En definitiva, y en palabras de OlABE (2013): "No es sostenible, salvo en casos excepcionales y en montes muy especiales, elaborar proyectos de ordenación como los actuales".
Por esa razón, y según relata el propio OLABE (2013), desde 2010 la administración forestal de la Comunidad Foral de Navarra ha iniciado una nueva estrategia planificadora más sencilla, ágil, barata y ajustada a la realidad de la propiedad forestal, que se basa en considerar como proyecto de ordenación la conjunción de dos tipos de documentos: un Plan Comarcal, que incluye una planificación "paraguas" para un determinado territorio, y un documento de planificación específica para cada monte o Plan de actuaciones. Esta interesante solución permite aglutinar en el Plan Comarcal, elaborado y financiado por la administración forestal, toda la información cuyo análisis a nivel individual de monte no tiene sentido, como la referente a socioeconomía, riesgo de incendios, medio natural, fauna o flora protegidas, espacios naturales, plagas y enfermedades, herramientas de cubicación, directrices de gestión selvícola y recomendaciones de conservación, incluyendo también la correspondiente a más de un $90 \%$ de los indicadores requeridos para la certificación forestal. Además, es posible revisar estos documentos comarcales incluyendo nuevos indicadores de certificación, normativas o cualquier avance relativo a las ciencias relacionadas con la gestión forestal, sin necesidad de modificar una gran cantidad de proyectos de ordenación individuales y sin coste alguno para los propietarios. De esta manera, los Planes de actuaciones se pueden limitar a lo estrictamente imprescindible, centrándose fundamentalmente en determinar los tipos de sistemas forestales presentes y las actuaciones a realizar en un período de 10 años. Por tanto, estos documentos son simples y baratos, por lo que pueden ser perfectamente aplicados a las fincas privadas de pequeña superficie (aunque no exclusivamente). Además, los indicadores de certificación forestal exigidos a este nivel de monte son muy pocos, por lo que la certificación de esas pequeñas superficies puede conseguirse sin grandes esfuerzos para el propietario. En VAL et al. (2013) se puede consultar la metodología de elaboración y el contenido de estos Planes de actuaciones, que constan de una plantilla que se divide en cinco apartados (Superficies y titularidad; Tipología de masas forestales y estimación de existencias; Otros aspectos relacionados con el medio y la gestión realizada; Plan de actuaciones; y Anexos). 
El territorio forestal de Navarra (unas $650.000 \mathrm{ha})$ se ha dividido en tres grandes comarcas biogeográficas: Atlántica, Pirineos y Mediterránea. Actualmente se cuenta con el Plan Comarcal de la primera de ellas y se está concluyendo el de la segunda. Los primeros resultados de esta estrategia confirman un ahorro considerable en la elaboración y certificación de los nuevos Planes de Actuaciones, muchos de los cuales corresponden a montes de pequeña superficie, así como en las revisiones de los proyectos de ordenación existentes (Olabe, 2013; VAL et al., 2013).

Castilla y León fue la primera comunidad autónoma que aprobó unas instrucciones de ordenación propias, las Instrucciones Generales para la Ordenación de los Montes Arbolados en Castilla y León (Decreto 104/1999, de 12 de mayo de 1999; BOCyL núm. 94, de 19 de mayo de 1999). Esta norma sigue la filosofía de las IGOMA de 1970, aunque con importantes mejoras, actualizaciones y añadidos en cuanto a la orientación, estructura y contenido de los instrumentos de gestión que considera, que son los Proyectos de ordenación y los Planes dasocráticos. Esta última figura, que sustituye a los Planes técnicos de ordenación de montes de 1971, se concibe como un instrumento de gestión simplificado, pero no provisional, con un inventario y planificación más sencillos, con el objeto de aplicarlos preferentemente en aquellos montes "cuya importancia forestal no requiera una intensidad de gestión como la que presupone un Proyecto de ordenación" (Art. 279). Ese mismo artículo de las Instrucciones cita cuatro posibles ámbitos de aplicación de los Planes dasocráticos, entre los que se encuentran los "montes de particulares, salvo que la importancia de sus aspectos productores y protectores, su extensión suficiente o el interés del propietario los haga sujetos de Proyectos de ordenación".

Para la realización de cualquiera de esas dos figuras de instrumentos de gestión en Castilla y León se ha venido utilizando un formulario en el que, además, se contempla la posibilidad de un tercer documento denominado Plan técnico de gestión de montes, fundamentalmente utilizado para montes privados. Según el Plan Forestal de Castilla y León (Decreto 55/2002, de 11 de abril; $B O C y L$ de 17 de abril de 2002), esta figura se ha concebido como un instrumento de planificación para los montes en los que resulta necesario integrar distintos usos y aprovechamientos que afectan a zonas arboladas y desarboladas y cuya gestión no puede abordarse ni planificarse de forma parcial o sectorial porque cada uso o aprovechamiento queda condicionado por los demás. Recientemente, esos formularios se han sustituido por una aplicación informática GIS denominada PLANFOR, que facilita la elaboración de los documentos de planificación forestal según los formatos oficiales de la administración forestal castellano-leonesa, expuestos en las Instrucciones de Normalización de la Planificación Forestal de Castilla y León (ITPLANFOR).

Por otra parte, en esta comunidad autónoma también existen unas Instrucciones para la redacción de Planes Técnicos de chopos en Castilla y León, con sus correspondientes plantillas digitales, que lógicamente van dirigidas a la ordenación de las numerosas choperas de la región, mayoritariamente de propiedad privada.

Además, en Castilla y León se están elaborando cuatro Planes de Ordenación de los Recursos Forestales (PORF), que corresponden a la Montaña Occidental de León, la Comarca de Almazán, la Provincia de Valladolid y el Sur de Burgos.

A pesar de todo el trabajo realizado, Castilla y León posee escasamente un $3 \%$ de su superficie forestal privada ordenada (Figura 3), pero hay que tener en cuenta que esta comunidad autónoma es una de las de mayor superficie de montes de esta titularidad, con cerca de 2,5 Mha (MAGRAMA, 2012).

En Andalucía se aprobaron en 2004 las Instrucciones Generales para la Ordenación de Montes de la Comunidad Autónoma Andaluza (Orden de 26 de enero de 2004; BOJA núm. 25, de 6 de febrero de 2004), y de manera adicional a las mismas existe un extenso manual en el que se amplía y se detalla su aplicación (JUNTA DE ANDALUCIA, 2004). Estas Instrucciones siguen una estructura similar a la de las IGOMA (1970) y consideran las figuras ya existentes en la normativa de ámbito nacional: Proyectos de ordenación de montes y Planes técnicos de ordenación. Éstos últimos se orientan fundamentalmente a los montes privados y se consideran la herramienta de relación de los propietarios con la administración, que los utiliza como base técnica 
para expedir autorizaciones y conceder subvenciones o exenciones fiscales. El esfuerzo realizado en Andalucía para ordenar los montes de titularidad particular la ha convertido en la segunda comunidad autónoma, tras Cataluña, con mayor porcentaje (un 15,2\%) de superficie privada ordenada (Figura 3), dato que adquiere más relevancia si se considera que la mayor superficie de este tipo de montes de todo el estado se encuentra en Andalucía, sumando algo más de 3,3 Mha (MAGRAMA, 2012).

Desde el año 2010 existen unas Instrucciones de ordenación de montes de la Comunidad de Madrid (SANJUANBENITO, 2011), pero de momento son exclusivamente de aplicación para los montes gestionados por la administración forestal madrileña, y no obligatorias para los montes privados (Resolución $n^{\circ}$ 2010-492/ADPF). Estas Instrucciones incluyen las mismas figuras de instrumentos de gestión que incluían las IGOMA, es decir, Proyectos de ordenación y Planes técnicos de gestión forestal, ambas de aplicación a montes públicos y privados. No establecen un articulado específico para los Planes técnicos de gestión forestal, sino que se les aplica el mismo esquema que a los proyectos de ordenación pero simplificado, especialmente en el apartado de inventario, de tal manera que se pueden presentar los datos utilizando los estadillos diseñados para las diferentes partes del proyecto, acompañados de una breve explicación que justifique las principales decisiones adoptadas en la planificación y la cartografía del proyecto. Los montes madrileños cuya superficie forestal sea inferior a 250 hectáreas podrán ordenarse mediante un Plan técnico de gestión forestal, excepto los de utilidad pública y los de propiedad de la propia Comunidad de Madrid, que deberán disponer de un Proyecto de ordenación cuando su superficie forestal sea superior a 100 ha.

Aunque las Instrucciones de la Comunidad de Madrid son muy recientes, la actividad ordenadora en la región ha sido impulsada de forma muy notable desde la aprobación de su Plan Forestal en el año 2000, habiéndose conseguido ordenar, según la última información disponible, el $21,4 \%$ de la superficie forestal total y cerca del $13,5 \%$ de la de titularidad privada. En el caso de las propiedades particulares, la práctica totalidad de la superficie ordenada en los 10 últi- mos años ha contado con subvenciones establecidas al efecto (SANJUANBENITO, 2013).

Otro caso es el del País Vasco, donde el Decreto Foral 61/2010 establece las Disposiciones generales reguladoras del contenido, aprobación, revisión y seguimiento de los Planes Técnicos de Gestión Forestal Sostenible o PTGFS (BOTHA 145, de 24 de diciembre de 2010).

Por su parte, la comunidad castellano-manchega cuenta con un Manual para la redacción de instrumentos de gestión forestal sostenible en Castilla-La Mancha (MARTíneZ et al., 2011), en el que se cita la existencia de un borrador de Instrucciones de ordenación que todavía no ha sido formalmente aprobado.

En la Región de Murcia se ha publicado recientemente una Instrucción dirigida a la interpretación de las Normas Generales existentes para el Estudio y Redacción de los Planes Técnicos de Gestión Forestal Sostenible en el ámbito de la Región de Murcia (BORM 152, de 5 de julio de 2011), es decir, aclarando la manera de aplicar en la región las todavía vigentes NGPTMA de 1971.

En algunas de las restantes comunidades autónomas del estado (excluyendo a Galicia, que se trata en el siguiente apartado) existen distintas normas referentes a la ordenación de montes, e incluso varias iniciativas de instrucciones (por ejemplo, en Extremadura), pero sin aprobar de momento.

\section{EL CASO DE GALICIA}

Galicia es la comunidad autónoma española más relevante desde el punto de vista forestal, pues aunque su territorio apenas supone un 5,8\% de la superficie total nacional, anualmente aporta entre el 50 y el $60 \%$ de la madera cortada en España (MAGRAMA, 2010, 2012; CONFEMADERA HÁBITAT Galicia, 2012). Además, cuenta con una tasa de extracción del $82,2 \%$, y la diferencia respecto al resto del estado queda reflejada en el hecho de que si no se tuvieran en cuenta los datos de Galicia la tasa de extracción en España bajaría al 17\% (MAGRAMA, 2012).

Según los datos del IFN4 o $4^{\circ}$ Inventario Forestal Nacional (MMAMRM, 2011b), un $68,6 \%$ del territorio de Galicia corresponde al 
uso forestal, lo que supone poco más de 2 Mha, como se indica en la Tabla 7.

De esta manera, Galicia es una de las primeras comunidades autónomas españolas en cuanto a porcentaje de superficie forestal, sólo por detrás de Canarias (76\%) y Asturias (72\%), y con un valor similar al de Cantabria y el País Vasco (SECF, 2011). Por otra parte, la superficie forestal de Galicia representa un 7,3\% del total forestal español y, en valor absoluto, ocupa el sexto lugar nacional, por detrás de Castilla-León, Andalucía, Castilla-La Mancha, Extremadura y Aragón (MAGRAMA, 2012).

La distribución de la superficie forestal de Galicia según el IFN4 se muestra en la Tabla 8, donde lo más destacable es el elevado porcentaje de superficie desarbolada existente, que supone casi el $30 \%$. Si a esto se une la posibilidad de mejora cualitativa de la selvicultura que se viene aplicando, es posible afirmar que todavía se puede incrementar notablemente el peso del sector forestal gallego.

En cuanto a las formaciones arboladas existentes en Galicia, el IFN4 indica que un 30,7\% corresponde a masas puras de coníferas (Pinus pinaster, $P$. radiata y $P$. sylvestris principalmente y por este orden de importancia), un $20,3 \%$ a eucaliptales (principalmente Eucalyptus globu- lus, pero creciendo en los últimos años la proporción de E. nitens), un $17,7 \%$ a especies de producción en mezcla o con frondosas autóctonas, un $29,3 \%$ a frondosas puras o en mezcla (siendo Quercus robur la especie más abundante, junto con $Q$. pyrenaica, Castanea sativa, Betula spp. y otras), así como un 2,0\% a arbolado ralo (zonas con una fracción de cabida cubierta inferior al 20\%).

Como puede comprobarse, la mayor parte de la superficie forestal gallega está poblada por plantaciones de especies de crecimiento rápido, o masas derivadas de antiguas plantaciones. La elevada productividad forestal que se consigue en Galicia se debe a las óptimas condiciones de su medio natural para el desarrollo de la riqueza forestal, aun a pesar de la falta de una selvicultura moderna y de la aplicación de la mejora genética (CONFEMADERA HÁBITAT GaliCia, 2012).

En efecto, la elevada disponibilidad hídrica y el régimen térmico suave de las zonas litorales de Galicia permiten extender el período vegetativo a todo el año en muchas estaciones (DíaZFIERROS et $a l ., 1983$ ), por lo que pueden considerarse climáticamente de primera calidad a nivel productivo, perteneciendo a la clase I de potencialidad productiva potencial definida por Gandullo y SerRada (1977). Aplicando una

\begin{tabular}{|l|r|r|}
\hline Usos del suelo & Superficie (ha) & \% \\
\hline Forestal & $2.030 .681,0$ & 68,6 \\
\hline Agrícola & $822.626,9$ & 27,8 \\
\hline Elementos artificiales & $81.520,6$ & 2,8 \\
\hline Agua & $20.307,4$ & 0,7 \\
\hline Humedal & $2.311,6$ & 0,1 \\
\hline Total & $2.957 .447,5$ & 100,0 \\
\hline
\end{tabular}

Tabla 7. Distribución de usos del suelo en Galicia según el IFN4 (MMAMRM, 2011b)

\begin{tabular}{|l|r|r|}
\hline Distribución del uso forestal & Superficie (ha) & \% \\
\hline a) Monte arbolado total & $1.424 .094,2$ & 70,1 \\
\hline a.1) Monte arbolado & $1.387 .961,7$ & 68,3 \\
\hline a.2) Monte arbolado ralo & $27.988,6$ & 1,4 \\
\hline a.3) Talas & $8.143,9$ & 0,4 \\
\hline b) Monte desarbolado & $606.586,8$ & 29,9 \\
\hline Total forestal & $2.030 .681,0$ & 100,0 \\
\hline
\end{tabular}

Tabla 8. Distribución del uso forestal en Galicia según el IFN4 (MMAMRM, 2011b) 
correcta selvicultura, los crecimientos medios en las mejores estaciones de dichas zonas costeras podrían sobrepasar los $30 \mathrm{~m}^{3} \cdot \mathrm{ha}^{-1} \cdot \mathrm{año}^{-1}$ en el caso de Eucalyptus globulus (FERNÁNDEZ-LóPEZ, 1982) e incluso ser mayores para $E$. nitens, los 20 $\mathrm{m}^{3} \cdot \mathrm{ha}^{-1} \cdot \mathrm{año}^{-1}$ para Pinus radiata (SÁNCHEZRODRÍGUEZ et $a l ., 2003)$ y los $15 \mathrm{~m}^{3} \cdot \mathrm{ha}^{-1} \cdot \mathrm{año}^{-1}$ para P. pinaster (RODRÍGUEZ-SOALLEIRO, 1995), todos ellos por encima de la media a nivel europeo. El resto del territorio gallego (exceptuando las áreas por encima de los $1.200 \mathrm{~m}$ de altitud, donde el frío invernal restringe el crecimiento), puede asimilarse a la clase II de potencialidad productiva forestal (GANDULlo Y SERRADA, 1977), con limitaciones débiles por aridez o por frío, principalmente en toda la zona montañosa sublitoral (DíAz-FIERROS et al., 1983).

En definitiva, se puede afirmar que Galicia, junto con el resto de la Cornisa Cantábrica y el norte de Portugal, representa la zona forestalmente más productiva de todo el continente europeo, y por esa razón existe en la región una importante industria del sector.

Según el último informe de CONFEMADERA HÁbitat Galicia (2012), la industria de la madera y el mueble en Galicia está compuesta por unas 3.000 empresas, de las que el $37 \%$ pertenecen a la primera transformación (rematantes, aserraderos, tablero y pasta) y el $63 \%$ a la segunda (carpintería y mobiliario). Estas empresas se distribuyen por toda la geografía gallega, generando riqueza fundamentalmente en entornos rurales poco industrializados, de tal manera que en más de una veintena de comarcas representan una de las tres primeras fuentes de empleo. En total, el empleo directo en estas industrias alcanza los 20.000 trabajadores y el indirecto otros 50.000 , lo que supone que el $6,6 \%$ de la población activa gallega trabaja en este sector. La facturación conjunta del sector en 2012 ascendió a $1.625 \mathrm{M} €$, y el valor de las exportaciones de madera, pasta y mobiliario de Galicia fue de $688 \mathrm{M} €$. Estas magnitudes del sector forestal en Galicia se resumen en que la industria de la madera y el mueble supone el $3,5 \%$ del PIB de la región.

A pesar de la extraordinaria riqueza y potencialidad productiva del monte gallego, así como de su importancia para la economía de la región, y especialmente para el medio rural, existen varias e importantes limitaciones a la producción forestal en Galicia, de las que destacan dos: los incendios y la estructura de la propiedad.

Sin entrar en mayores consideraciones, pues no es el objeto del presente trabajo, los incendios forestales son la verdadera "plaga" de los montes gallegos. Según los datos de la propia Xunta de Galicia (2012), durante el período 2002-2011 se quemaron anualmente más de 31.000 ha como media (con un "pico" de casi 96.000 ha en el año 2006), y sin ninguna duda todas las tareas relacionadas con la prevención y defensa contra incendios reclaman año tras año un muy elevado porcentaje de los presupuestos de la administración forestal gallega. Como ya se conoce por la experiencia en otros lugares, precisamente la ordenación de montes y la certificación forestal podrían ser instrumentos estabilizadores en lo que respecta a la disminución del número de incendios.

En cuanto a la estructura de la propiedad, Galicia es la comunidad autónoma con el mayor porcentaje de superficie forestal privada del estado (casi el 98\%), como ya se indicó en la Figura 1 , por lo que es en esta región donde resulta mayor el reto de ordenar los montes particulares.

En la Tabla 9 se presenta la distribución de la superficie forestal gallega por el tipo de propiedad, realizando una estimación entre los datos del IFN3 (XUNTA DE GALICIA, 2001) y del IFN4 (MMAMRM, 2011b), puesto que en el último se han excluido de este análisis los montes de los que no se dispone de información, que son mayoritariamente los de titularidad privada individual. Como puede observarse, algo más de dos terceras partes de los montes de Galicia son particulares individuales o familiares, y prácticamente el resto son montes vecinales en mano común (también privados, pero colectivos).

El origen histórico de este reparto del suelo en Galicia proviene del sistema tradicional de aprovechamiento de los montes. A grandes rasgos, este sistema se caracterizó por el usufructo en común por parte de los vecinos (sistema de foros) de las tierras de monte, consideradas como un complemento esencial de las pequeñas explotaciones agro-ganaderas (fertilización, pastos, madera, leña, etc.), siendo el origen de los montes vecinales en mano común y de los montes privados proindivisos. Posteriormente, y gracias 


\begin{tabular}{|l|r|r|}
\hline Titularidad & Superficie (ha) & \% \\
\hline Montes públicos & $30.232,7$ & 1,5 \\
\hline Montes vecinales en mano común & $620.313,0$ & 30,5 \\
\hline Montes particulares & $1.380 .135,3$ & 68,0 \\
\hline Total & $2.030 .681,0$ & 100,0 \\
\hline
\end{tabular}

Tabla 9. Distribución de los tipos de propiedad forestal en Galicia según el IFN3 y el IFN4 (XUNTA DE GALICIA, 2001; MMAMRM, 2011b)

principalmente a apropiaciones de pequeñas parcelas del común, repartos de montes, redenciones forales y al proceso desamortizador del siglo XIX, una gran parte de la superficie forestal pasó a manos de particulares, no sin originar numerosos conflictos en el medio rural (GUITIÁN, 1989; BAlboA, 1990; PÉreZ-ANTElo, 1995).

Para comprender bien la estructura de la propiedad en Galicia es necesario, además, relacionar los datos anteriores con el número de propietarios y el tamaño de sus montes.

En el caso de los montes privados familiares, se estima que existen en Galicia algo más de 600.000 propietarios (aunque esta información debe manejarse con cautela a falta de datos más actualizados y fiables), lo que significa una superficie media de las propiedades de entre 1,5 y 2 ha, que a su vez se dividen en numerosas parcelas cuya superficie media no alcanza las 0,25 ha (XUNTA DE Galicia, 1992). Este hecho, lógicamente, dificulta enormemente su ordenación debido a su baja rentabilidad, a pesar de estar pobladas en gran parte por especies de rápido crecimiento.

En cualquier caso, estos minifundios forestales ocupan los terrenos de mejor productividad forestal y una alta proporción del terreno arbolado, por lo que aportan la mayor parte de la madera producida en Galicia. El sistema de aprovechamientos más generalizado en este tipo de propiedad es la "corta de oportunidad", es decir, el monte es un complemento a otras actividades, agrícolas o ganaderas, por lo que se convierte en una especie de "hucha" o "seguro" al que acudir cuando se necesita dinero, despreocupándose los propietarios, generalmente, de aplicarle los cuidados culturales adecuados. También contribuye a ello el hecho de que muchos propietarios de terrenos forestales viven actualmente en las ciudades, y solamente van a sus propiedades en contadas ocasiones. Por eso, cuando se deciden por plantar, lo hacen general- mente con especies de turno corto y aplican posteriormente una escasa o nula selvicultura, tratando así de rentabilizar una tierra a la que no quieren (o no pueden) dedicar tiempo ni recursos económicos. El envejecimiento de la población rural está provocando un efecto similar de abandono de los montes en Galicia. Todas las consideraciones comentadas en los apartados anteriores sobre la dificultad de ordenar los montes de pequeño tamaño son perfectamente aplicables al caso gallego, que se puede considerar el paradigma de esta problemática.

A pesar de lo anterior, se estima que en el año 2012 más de 54.200 propietarios cortaron madera en Galicia, lo que significa que el $7 \%$ de las familias gallegas percibió algunos ingresos por su venta, que en total alcanzaron más de $250 \mathrm{M€}$ (CONFEMAdERA HÁBITAT GALICIA, 2012). En esta coyuntura de crisis, el monte gallego sigue siendo un recurso económico que utilizan muchas familias para obtener una renta complementaria.

Por otra parte, los montes vecinales en mano común (MVMC), como ya se mencionó en la introducción, son una figura de propiedad particular colectiva de tipo germánico, que pertenecen a los vecinos comuneros que viven en un determinado terreno y que los aprovechan sin asignación de cuotas. Representan casi una tercera parte de la superficie forestal gallega (Tabla 9), pero ocupan los terrenos de peor calidad y solamente en un pequeño porcentaje (cercano al 25\%) se encuentran arbolados (XUNTA DE Galicia, 1992). Se distribuyen en las cuatro provincias, siendo Ourense la que cuenta con mayor superficie de MVMC y A Coruña la que menos. Una gran proporción de estos montes están gestionados por la administración forestal mediante convenios o consorcios. Se estima que existen cerca de 2.800 MVMC en Galicia, con una superficie media próxima a las 233 ha, por lo que en este caso sí poseen un tamaño medio 
que permite la organización adecuada de su aprovechamiento forestal mediante proyectos de ordenación o planes similares.

Para tratar de ordenar los montes de Galicia, la administración forestal gallega ha realizado un importante esfuerzo desde mediados de la última década del pasado siglo, a partir del establecimiento de una serie de ayudas para la elaboración de Proyectos de ordenación y Planes técnicos, pero también con la creación en 1998 del Registro de Proyectos de Ordenación y Planes Técnicos de Gestión de Montes (Orden de 12 de junio; $D O G$ núm. 115, de 17 de junio de 1998). A partir de la orden de ayudas del año 2002 (Orden de 31 de mayo de 2002 de fomento de la selvicultura y de la ordenación de montes arbolados; DOG núm. 109, de 7 de junio de 2002), se estableció la obligatoriedad de presentar cierta información de los planes de gestión en soporte informático, siguiendo las Instrucciones para la estructura y codificación de los planes de gestión forestal, que se complementaban con el Manual para el seguimiento práctico de las instrucciones de estructura y codificación de los planes de gestión. Con ello se pretendía unificar el contenido mínimo y la forma de presentar la información de los planes de gestión (Proyectos de ordenación o Planes técnicos), facilitando el seguimiento y control de lo planificado en los mismos, así como la explotación de la información que contienen. Estas instrucciones, que no pueden considerarse como unas verdaderas instrucciones de ordenación, incluían el esquema o requerimientos mínimos que deberían tener los planes de gestión, siguiendo una estructura muy similar a la propuesta en las IGOMA (1970) pero con algunas variaciones, dirigidas sobre todo a recoger la información sobre los criterios e indicadores de gestión forestal sostenible requerida en el proceso de certificación según las normas PEFC.

Los resultados de estas iniciativas son las cerca de 200.000 ha ordenadas actualmente en Galicia, de las cuales algo más de 185.000 corresponden a montes privados, pero considerando la altísima proporción de terrenos de titularidad particular de la región (casi el 98\%, Figura 3), estas cifras significan que solamente un $9 \%$ de la superficie forestal particular gallega está ordenada (MAGRAMA, 2012). Además, la gran mayo- ría de las ordenaciones corresponden a montes vecinales en mano común, y fundamentalmente a los gestionados mediante consorcios o convenios por la propia Xunta de Galicia. Por otra parte, y según los datos de los propios sistemas de certificación, en Galicia hay cerca de 10.400 ha certificadas por FSC y casi 167.000 ha por PEFC (abril de 2013), que representan respectivamente un 0,7 y un $11,7 \%$ de la superficie arbolada de la comunidad, porcentajes realmente bajos para la región más importante forestalmente de España.

Por tanto, el esfuerzo en Galicia debe dirigirse, en gran medida, a ordenar y certificar los minifundios particulares, especialmente teniendo en cuenta su comentada importancia superficial y productiva.

En ese sentido, el nuevo esfuerzo ordenador de la administración gallega viene reflejado en el establecimiento de la figura de las Sociedades de Fomento Forestal (SOFOR) y, especialmente, en la reciente aprobación de la Ley de Montes de Galicia en 2012.

Las SOFOR (Decreto 45/2011, de 10 de marzo; DOG núm. 58, de 23 de marzo de 2011; Corrección de errores DOG núm. 103, de 30 de mayo de 2011) son agrupaciones voluntarias de propietarios forestales reunidos en sociedades mercantiles de responsabilidad limitada. Sus finalidades son fomentar la gestión sostenible mediante la agrupación voluntaria de terrenos forestales que permita una rentabilidad económica y la consiguiente consolidación de la propiedad, reduciendo a la vez el abandono del monte gallego y disminuyendo el riesgo de incendios.

Por su parte, la Ley de Montes de Galicia (Ley 7/2012, de 28 de junio; DOG núm. 140, de 23 de julio de 2012) reconoce la enorme importancia y la necesidad de fomentar la ordenación de los montes de la comunidad. Para ello establece la elaboración de unas Instrucciones generales de ordenación de montes (Art. 78), que contendrán los principios rectores, criterios y requisitos que deberán cumplir todos los instrumentos de ordenación y gestión (como los denomina la propia ley) de los montes gallegos, así como su estructura y contenidos mínimos. En el Art. 79 se enumeran y describen las categorías de esos instrumentos de ordenación o gestión forestal a aplicar en los montes de Galicia, que son el conocido Proyecto de ordenación (conve- 
nientemente actualizado) y, como novedad, dos nuevos documentos ideados respectiva y específicamente para la ordenación de las propiedades forestales privadas de pequeño tamaño y para fomentar las agrupaciones de propietarios: el Documento simple de gestión y el Documento compartido de gestión.

El Documento simple de gestión se define como un instrumento de gestión forestal que planifica las mejoras y aprovechamientos de los recursos forestales, maderables y no maderables, garantizando una gestión forestal sostenible de la superficie de una misma propiedad, sin que ningún coto redondo supere las 25 ha.

El Documento compartido de gestión, por su parte, se concibe como un instrumento de gestión forestal de iniciativa privada para un conjunto de propietarios, donde ninguna superficie de una misma propiedad supere las 25 ha en coto redondo. Debe incluir unos referentes de buenas prácticas, una planificación simple de los aprovechamientos de los recursos forestales, maderables y no maderables, y modelos selvícolas para los principales tipos de masa, de obligado cumplimiento para los terrenos forestales adscritos al mismo.

La Ley reserva la figura del Proyecto de ordenación para los montes públicos, los protectores y los de gestión pública, así como para todos los montes de particulares superiores a 25 ha en coto redondo de una misma propiedad.

En el caso de los montes vecinales en mano común, cuando tengan un tamaño superior a las 25 ha deberán dotarse de un Proyecto de ordenación, o de un Documento simple de gestión si su superficie es inferior o igual a 25 ha. Lo mismo se establece para las agrupaciones forestales formalmente constituidas, los montes de varas, abertales, de voces, de vocerío o de fabeo, pero considerando el límite de las 25 ha en coto redondo.

Por otra parte, la Ley indica que la administración forestal elaborará Planes de ordenación de recursos forestales (PORF), preferentemente para cada uno de los 19 distritos forestales en los que se divide Galicia, y describe el procedimiento de elaboración y aprobación de los mismos, así como su contenido mínimo. Además, en el Art. 76.3 se establece que previamente a la aprobación de un PORF se podrán elaborar unos modelos selvícolas orientativos y unos referentes de buenas prácticas por distrito forestal, con la finalidad de permitir la adhesión a los mismos de propietarios de montes de particulares, pero siempre y cuando su superficie sea inferior o igual a 25 ha para los montes vecinales en mano común, o inferior o igual a 25 ha en coto redondo para los montes de particulares, agrupaciones forestales formalmente constituidas, montes de varas, abertales, de voces, de vocerío o de fabeo. Se entiende que estas adhesiones tienen sentido con la existencia de los PORF correspondientes, que supondrían una planificación "paraguas" para un determinado distrito, de manera similar, en cierto modo, al modelo adoptado en la Comunidad Foral de Navarra.

Para desarrollar adecuadamente lo dispuesto en la Ley de Montes gallega, se está trabajando y ya existe un primer borrador de Instrucciones generales de ordenación de montes de Galicia, que definen la estructura y el contenido de los mencionados instrumentos de ordenación o gestión forestal en la comunidad autónoma de Galicia. El objetivo general perseguido ha sido proponer unos documentos más actuales y adaptados a las nuevas tecnologías, que respondan a los nuevos intereses de la sociedad respecto al uso múltiple y sostenible del monte y que sirvan para dar soporte a la creciente demanda de certificación forestal. A la vez se pretende que sean lo más simples posible para que puedan ser asumidos por los propietarios de pequeñas superficies y por las necesarias agrupaciones de los mismos, así como por las comunidades de montes vecinales. Con esas finalidades, las consideraciones que se han seguido para la elaboración del borrador de las Instrucciones de ordenación gallegas han sido las siguientes:

1. Desarrollar un documento de contenidos mínimos que pueda aplicarse a los tres tipos de instrumentos de ordenación o gestión establecidos en la Ley de Montes de Galicia (es decir, proponer una estructura conjunta para los Proyectos de ordenación, los Documentos simples de gestión y los Documentos compartidos de gestión), que permita un escalado gradual del inventario y de la planificación en función del tamaño y complejidad de la superficie a ordenar, y que sea flexible a los cambios que se produzcan durante su vigencia.

2. Mantener la estructura clásica y el contenido básico que tradicionalmente recogen los 
documentos de ordenación de montes, pero simplificándolo al máximo posible para facilitar su extensión a la mayor cantidad posible de propiedades forestales de Galicia. Así, por ejemplo, se actualiza y simplifica el inventario forestal, pudiendo utilizarse las herramientas selvícolas (simuladores informáticos de crecimiento y producción, etc.) elaboradas por la Unidade de Xestión Forestal Sostible (UXFS) de la Universidad de Santiago de Compostela (DiÉguezARANDA et al., 2009; actualizado en http://www.usc.es/uxfs/), así como otras modernas tecnologías (datos LIDAR, etc.), y se simplifica también la planificación con la consideración de modelos selvícolas orientativos preestablecidos.

3. Incluir en el contenido mínimo y común de los instrumentos de ordenación o gestión los requerimientos comunes a los dos sistemas de certificación forestal establecidos en España (FSC e PEFC).

4. Incluir adecuadamente lo dispuesto en otras normas legales referentes a la gestión de montes, y muy especialmente lo establecido en la propia Ley de Montes de Galicia y en la Ley de Prevención y Defensa contra los Incendios Forestales de Galicia (Ley 3/2007, de 9 de abril; $D O G$ núm. 74, de 17 de abril de 2007; Corrección de errores DOG núm. 96, de 21 de mayo de 2007).

5. Diseñar una estructura que permita crear una aplicación vía web para facilitar la elaboración, aprobación y seguimiento de los instrumentos de ordenación o gestión forestal mediante:

- La recuperación de la información de fuentes existentes (SixPac, Mapa Forestal, SITGA-IDEG, etc.).

- La máxima automatización de los cálculos.

- La inclusión de bases de datos con la información codificada.

- La generación automática del informe que deberá presentarse a la administración correspondiente.

- El seguimiento de las actuaciones forestales por parte de la administración y del propio gestor.
Una vez que sean aprobadas las Instrucciones generales de ordenación de montes de Galicia va a ser imprescindible, además de fomentar la elaboración de los PORF de los distritos, una importante labor de extensión forestal, para explicar lo que significa y cómo se consigue en la práctica la gestión sostenible de los montes, tanto en el medio rural como, incluso, en la sociedad en general.

El éxito de estas iniciativas dasocráticas gallegas puede suponer un aumento de la superficie arbolada y un incremento de la producción (en cantidad y calidad) de los montes ya poblados, así como la desactivación de conflictos y problemas como el de los incendios. Todo ello supondría el tan ansiado aumento de la calidad de vida en el medio rural de Galicia.

\section{CONCLUSIONES}

La superficie forestal de España está ocupada de forma mayoritaria por montes privados que, a la vez, son los más productivos, a pesar de la desfavorable dispersión de este tipo de propiedades en minifundios forestales y de la escasa proporción de las mismas que se encuentran ordenadas (y mucho menos certificadas). Esto quiere decir que una parte significativa a nivel nacional de las cortas de madera (y de la gestión del resto de recursos forestales) se lleva a cabo sin la necesaria organización en el tiempo y el espacio que supone contar con un instrumento de gestión forestal vigente, y que las posibilidades de mejora en este sentido son muy amplias.

La reciente Ley de Montes estatal asigna un papel primordial a la ordenación de los terrenos forestales, estableciendo la obligatoriedad de ordenar todos los montes públicos y privados antes de febrero de 2019. Sin embargo, todavía no se han aprobado las Directrices básicas comunes de ordenación y aprovechamiento de montes que establece la propia Ley, por lo que han sido algunas de las comunidades autónomas las que han propuesto diferentes soluciones para tratar de ordenar y gestionar adecuadamente sus montes de titularidad privada.

Un examen de las iniciativas autonómicas más notables en este sentido indica que las soluciones aportadas son, en general, muy similares, 
y que todas ellas buscan instrumentos de gestión forestal que sean sencillos y estandarizados, fáciles y baratos de redactar, así como comprensibles, útiles y asumibles por los propietarios. Para ello, se propone evitar la acumulación innecesaria de información y permitir la recuperación de la existente en otras fuentes, simplificar el inventario (permitiendo y favoreciendo el uso de nuevas tecnologías, como datos LIDAR, etc.) y automatizar los cálculos todo lo posible, así como flexibilizar la planificación, utilizando tipologías de masa y modelos selvícolas prestablecidos. Por supuesto, todo ello debe estar apoyado por aplicaciones informáticas que faciliten la redacción de los documentos, integren todos los datos en sistemas de información geográfica y permitan un seguimiento documental sencillo por parte de la administración, así como de la propia gestión por parte de los propietarios.

Una de las opciones más interesantes para conseguir estos objetivos es aplicar un modelo de planificación forestal a dos niveles, que considere planes comarcales o PORFs por una parte, e instrumentos de gestión sencillos para cada propietario o gestor, basados en los anteriores. De esta manera, se conseguirá una proporcionalidad entre la complejidad de los instrumentos de ordenación y la de la gestión en las superficies correspondientes a los dos niveles de planificación.

Además, la aplicación de instrumentos de ordenación adaptados a las características y necesidades de los propietarios privados forestales permitirá mejorar la propia gestión, consolidar la propiedad, organizar la oferta diversa de bienes y servicios que estos montes pueden ofrecer y facilitar el acceso a la certificación. Todos estos beneficios supondrían una mejora evidente para el sector forestal español en su conjunto $\mathrm{y}$, en especial, para aquellas comunidades autónomas que cuentan con una mayor proporción o superficie de montes privados.

La certificación forestal ha tenido un papel muy importante en el diseño y en la aplicación de los instrumentos de gestión forestal propuestos desde las comunidades autónomas para ordenar los montes particulares de pequeño tamaño, fomentando a la vez las agrupaciones de propietarios. Las previsiones indican un crecimiento de las necesidades de certificación en los próximos años, por lo que las administraciones forestales deberían incrementar el empeño en esta tarea.

Otra de las iniciativas llevadas a cabo por las comunidades autónomas ha sido el fomento de las ordenaciones privadas mediante líneas de incentivos económicos y fiscales, pero hay que considerar lo dispuesto por la Ley de Montes al establecer la fecha de febrero de 2014 como límite para conceder esos beneficios a montes no ordenados.

Finalmente, no hay que olvidar que para ayudar al éxito de la ordenación de los montes privados resulta imprescindible que las administraciones forestales acometan una primordial labor de extensión forestal en el medio rural, acompañada de otra, no menos importante, de comunicación del sector forestal con la sociedad en general.

\section{Agradecimientos}

El grupo de investigación Unidade de Xestión Forestal Sostible (UXFS) está financiado por la Xunta de Galicia ("Programa de Consolidación y Estructuración de Unidades de Investigación Competitivas 2011"), con cofinanciación mediante fondos FEDER.

\section{BIBLIOGRAFÍA}

Adell, F.J. Y Fernández, G.; 2013. Las Directrices Básicas Comunes de Gestión Forestal Sostenible: una herramienta para facilitar la gestión de los montes en España. Cuad. Soc. Esp. Cienc. For. 37: 23-35.

AzPITARTE, J.; 2013. La planificación forestal en la propiedad privada. Cuad. Soc. Esp. Cienc. For. 37: 75-78.

BAlBOA, X.; 1990. O monte en Galicia. Edicións Xerais de GaliciaVigo.

CANTERO, A.; 2013. Nuevas formas de certificación forestal en el País Vasco. Cuad. Soc. Esp. Cienc. For. 37: 85-88.

CONFEMADERA HÁBITAT GALICIA; 2012. Informe de resultados 2012. Federación Gallega de Empresas de la Madera. 25 pp. Disponible en: www.confemaderagalicia.es

CPF; 2013. Centro de la Propiedad Forestal de Cataluña. Web oficial. http://www20.gencat.cat/ (consultado: mayo 2013). 
DÍAZ-FIERROS, F.; UCIEDA, F.; ReTUERTO, R.; CARBALLEIRA, A. Y TURC, L.; 1983. Productividad climática potencial de cultivos y bosques en Galicia. En: I Xornadas de Estudo sobor dos recursos básicos da agricultura galega. Edicións do Castro. Sada (A Coruña).

Diéguez-Aranda, U.; Rojo Alboreca, A.; CASTEdo-Dorado, F.; Álvarez GonzÁlez, J.G.; Barrio-Anta, M.; Crecente-Campo, F.; GonzÁlez GonzÁlez, J.M.; PérezCruzado, C.; Rodríguez Soalleiro, R.; López-SÁNCHEZ, C.A.; BalboA-Murias, M.A.; Gorgoso Varela, J.J. Y SÁnChez RODRÍGUEZ, F.; 2009. Herramientas selvícolas para la gestión forestal sostenible en Galicia. Consellería do Medio Rural, Xunta de Galicia. Santiago de Compostela.

Eraso, E. y Olabe, F.; 1998. Pliego de Condiciones Técnicas Generales de Ordenación de Montes. Gobierno de Navarra (inédito).

FAO; 2005. Evaluación de los Recursos Forestales Mundiales 2005. Hacia la ordenación forestal sostenible. Estudio FAO: Montes $\mathrm{n}^{\circ}$ 147. Roma. Disponible en: www.fao.org/docrep/009/a0400s/a0400s00. htm.

FARRIOL, R.; 2013. La planificación en los montes privados de Cataluña: nuevas instrucciones de redacción. Cuad. Soc. Esp. Cienc. For. 35: 79-84.

FERNÁNDEZ-LÓPEZ, A.; 1982. Evaluación del crecimiento y productividad del monte bajo de Eucalyptus globulus en rotaciones sucesivas. Premio Exc. Diputación de Pontevedra. (inédito).

GANDUllo, J.M. y SERRADA, R.; 1977. Mapas de productividad potencial forestal de la España Peninsular. INIA. Ministerio de Agricultura. Madrid.

García, O.; Vericat, P.; JuAnati, C. y OMEdes, P.; 2013. Nuevo marco de redacción para los proyectos de ordenación forestal en Cataluña. Cuad. Soc. Esp. Cienc. For. 37: 17-21.

GonzÁlez-Tato, R.; Rivas-Silvosa, M.; BeIroLAGO, M.; GONZÁLEZ-PÉrEZ, M.R.; TORRESMartínez, P.M. y Rojo-Alboreca, A.; 2013. La certificación FSC de agrupaciones de minifundios forestales de la comarca de Ortegal (A Coruña, Galicia). En: S.E.C.F. (ed.), Actas $6^{\circ}$ Congreso Forestal Español
6CFE1-443: 2-11. Sociedad Española de Ciencias Forestales. Vitoria-Gasteiz.

Guitian, L.; 1989. Propiedad del monte y ordenación forestal en Galicia. En: $V$ Coloquio de Geografía Agraria: 87-98. Departamento de Geografía, Universidad de Santiago de Compostela. Santiago de Compostela.

Hirsch, F.; KorotKov, A. \& Wilnhammer, M.; 2007. La propiedad privada de bosques en Europa. Unasylva 58(228).

JunTA DE ANDAluCÍA; 2004. Manual de ordenación de montes de Andalucía. Consejería de Medio Ambiente. Junta de Andalucía. Sevilla.

MADRIGAL, A; 1994. Ordenación de montes arbolados. Colección Técnica. ICONA. Madrid.

MAGRAMA; 2010. Anuario de estadística forestal 2010. Ministerio de Agricultura, Alimentación y Medio Ambiente. Madrid. Disponible en: http://www.magrama.gob.es/es/biodiversidad/estadisticas/forestal_anuarios_todos.aspx

MAGRAMA; 2012. Criterios e Indicadores de gestión forestal sostenible en los bosques españoles. Ministerio de Agricultura, Alimentación y Medio Ambiente, Secretaría General Técnica, Centro de Publicaciones. Madrid. Disponible en: http://www.magrama.gob.es/es/biodiversidad/temas/politica-forestal/politica-forestal-en-espana/index.aspx

Martínez, S.; Prieto, A.; Díaz-Balteiro, L. Y SAURA, S.; 2011. Manual para la redacción de instrumentos de gestión forestal sostenible en Castilla-La Mancha. Dirección General de Política Forestal, Consejería de Agricultura y Medio Ambiente, Junta de Comunidades de Castilla-La Mancha. Toledo.

MMAMRM; 2011a. Criterios e indicadores de gestión forestal sostenible 1990-2010. (Elaborados para el Informe sobre el "Estado de los bosques europeos 2011" que se presentó en la Conferencia Ministerial para la Protección de los Bosques de junio 2011). Ministerio de Medio Ambiente y Medio Rural y Marino, Dirección General de Medio Natural y Política Forestal, Secretaría de Estado de Cambio Climático, Área de Inventario y Estadística Forestal. Madrid. Disponible en: http://www.magrama.gob.es/es/biodiversidad/estadisticas/C\&I _version_web_definitva_tcm7-186904.pdf 
MMAMRM; 2011b. Cuarto Inventario Forestal Nacional. Galicia. Ministerio de Medio Ambiente y Medio Rural y Marino, Dirección General de Medio Natural y Política Forestal. Madrid.

MONTERO, E.; 2008. Aplicación de la ordenación por rodales en Navarra. Experiencias y valoraciones. Cuad. Soc. Esp. Cienc. For. 27: 21-28.

Olabe, F.; 2013. Nueva propuesta de planificación forestal. Cuad. Soc. Esp. Cienc. For. 37: 9-15.

Pérez-Antelo, A.; 1995. Comentarios sobre la evolución de los bosques gallegos hasta comienzos del siglo XX. Montes 41: 5-14.

Piqué, M.; Vericat, P.; Cervera, T.; Baiges, T. Y FARRIOL, R.; 2013. Tipologías forestales y modelos de gestión: bases para la planificación forestal en el contexto actual. Cuad. Soc. Esp. Cienc. For. 37: 57-65.

Portabella, B.; Farriol, R. y VAlero, J.; 1995. Conclusiones sobre la aplicación de los Planes Técnicos de Gestión y Mejora Forestal en fincas de titularidad privada en Cataluña. Cuad. Soc. Esp. Cienc. For. 1: 185-189.

RodríGueZ-SoAlleiro, R.; 1995. Crecimiento y producción de masas forestales regulares de Pinus pinaster Ait. en Galicia. Alternativas selvícolas posibles. Tesis doctoral. Universidad Politécnica de Madrid. Madrid.

SÁNCHEZ-RODRÍGUEZ, F; RODRÍGUEZ-SOALLEIRO, R.; ROJO-AlboRECA, A.; ÁlVAREZ-GONZÁLEZ, J.G.; LÓPEZ-SÁNCHEZ, C.; GORGOSO, J. Y CASTEDO, F.; 2003. Crecimiento y tablas de pro- ducción de Pinus radiata D. Don en Galicia. Inves. Agrar., Sist. Recur. For. 12(2): 65-83.

SANJUANBENITO, P.; 2011. Ordenación de montes de la Comunidad de Madrid. Foresta (Especial Comunidad de Madrid) 52: 142-149.

SAnjuAnBenito, P.; 2013. La estructura de la propiedad forestal y la planificación en la Comunidad de Madrid. Cuad. Soc. Esp. Cienc. For. 37: 89-94.

SECF; 2011. Situación de los Bosques y del Sector Forestal en España. Informe 2010. Sociedad Española de Ciencias Forestales. Disponible en: http://www.secforestales.org/

Val, Y.; Olabe, F. y Sola, G.; 2013. Una respuesta a la demanda de los pequeños propietarios particulares. Cuad. Soc. Esp. Cienc. For. 37: 37-42.

Xunta De Galicia; 1992. Plan Forestal de Galicia. Síntesis. Consellería de Agricultura, Gandería e Montes. Dirección Xeral de Montes e Medio Ambiente Natural. Xunta de Galicia. A Coruña.

Xunta de Galicia; 2001. O monte galego en cifras. Dirección Xeral de Montes e Medio Ambiente Natural, Consellería de Medio Ambiente. Xunta de Galicia. Santiago de Compostela.

Xunta De Galicia; 2012. Plan de Prevención e Defensa Contra os Incendios Forestais de Galicia (PLADIGA 2012). Consellería do Medio Rural e do Mar. Xunta de Galicia. Santiago de Compostela. 